\title{
Breakdown of stimulus control by d-amphetamine
}

\author{
CYNTHIA SCHEUER and JOHN N. MOORE \\ Florida Atlantic University, Boca Raton, Florida 33432
}

\begin{abstract}
Six albino rats served as Ss in a series of experiments designed to determine the effects of d-amphetamine sulfate on behavior regulated by internal- and external-stimulus control. A two-bar switching schedule (with and without $\mathrm{S}^{\mathrm{D}}$ ) was utilized so that both perseveration and premature switching could be analyzed. All Ss, in all experiments, demonstrated increased variability under all drug contingencies. Both internal- and external-stimulus control broke down after the administration of the drug and was marked by general perseveration on the first bar. Transition behavior regulated by internal cues resulted in premature switching.
\end{abstract}

Laties and Weiss (1966) and Laties (1972) showed that pigeons' behavior patterns would be disrupted by injections of $d$-amphetamine in the absence of external-stimulus control. When benavior was signaled by external events, temporal discriminations involving correlated cues (Laties \& Weiss, 1966) and switching behavior signaled by an external cue (Laties, 1972) were shown to be unaffected by $1.0-\mathrm{mg} / \mathrm{kg}$ doses of amphetamine. The introduction and withdrawal of d-amphetamine has also been demonstrated to disrupt timing relationships in rats maintained on a DRL schedule of positive reinforcement (Carey, 1973). Carey found that both procedures (amphetamine introduction or withdrawal) reduced the frequency of short IRTs and increased medium IRTs, thus flattening the temporal gradient.

Recently, investigators have been concerned with the generality of experimental findings derived from prepared behaviors (such as keypecking in the pigeon) to unprepared (arbitrary) responses such as leverpressing in the rat (Seligman, 1970). They argue that the laws of learning may vary with the type of behavior selected for study. For example, pigeons are prepared to keypeck in appetitive situations, while rats are contraprepared to leverpress to avoid footshock. Therefore, keypecking in birds, in contrast to leverpressing in rats, should be more easily conditioned and, consequently, less susceptible to disruption by pharmacological agents. Following this line of argument, it is quite feasible that the absence of behavior disruption obtained by Laties in situations cued by external events is confined to those behaviors which are part of an organism's normal repertoire in appetitive situations. These prepared behaviors may be much more difficult to disrupt than arbitrary responses such as leverpressing. Therefore, one purpose of the present study was to investigate the generality of Laties's findings to an arbitrary behavior.

In addition, an attempt was made to determine the effects of d-amphetamine on the acquisition of internal-stimulus control, by not only looking at the drug's effects on steady-state behavior, but also during transition from a chain to a tandem schedule of positive reinforcement.

\section{METHOD}

\begin{abstract}
Subjects
Six male albino rats, approximately 90 days old at the start of training, served as Ss. All Ss were maintained on a 23-h-water-deprivation schedule with food consisting of Wayne Lab Chow Blox provided ad lib in the home cage. Animals were permitted $10 \mathrm{~min}$ of water following each experimental session.
\end{abstract}

\section{Apparatus}

Two modified operant-conditioning units were used for testing. Each unit was made with sides of clear Plexiglas and back and front walls of stainless steel. The inside dimensions of the unit were 9 in. wide $\times 8$ in. high. Two Gerbrands monkey levers were placed on adjacent walls, with Bar B on the same wall as the water dispenser. LVE water solenoid valves (Model 1527) provided reinforcement throughout the conduct of the study. Each unit was housed within a Styrofoam ice chest to attenuate extraneous visual cues. A small fan, mounted on the side of each unit, provided air circulating through the chamber, and, along with a 78-dB white masking noise, served to attenuate extraneous auditory cues. A $28-\mathrm{V}$ dc jeweled pilot light, mounted directly above Bar B served as the $\mathrm{S}^{\mathrm{D}}$ during the chain and fade phases of the experiment. All contingencies were programmed and recorded automatically by means of electromechanical switching circuits located in an adjoining room.

\section{Procedure}

Preliminary Training. Animals were shaped to depress Bar B for reinforcement, and then the requirement was raised so that $S$ had to depress Bar A once, and then depress Bar B to gain reinforcement. At the completion of a Bar $A$ response, the $S^{D}$ was turned on until a Bar $B$ response occurred. The response requirement on Bar A was gradually raised to a fixed consecutive number (FCN) reinforcement schedule consisting of eight or more responses on Bar A prior to switching to Bar B. If $S$ emitted fewer than eight responses on A prior to depression of $B$, the requirement was begun anew. Ss were stabilized on chain FCN 8 (A)-FR 1 (B) for 32 consecutive daily 1-h sessions. Stabilization was assumed when an individual's distribution of run lengths on A showed little day-to-day variation, and when the mode of the distribution fell at the same value for three consecutive daily sessions. The total number of Bar A and B responses, plus the number of reinforcements obtained, was recorded for each session. The major behavioral measure, however, consisted of the number of Bar A responses prior to a Bar $B$ response. These data were recorded in the form of a run-length distribution which ranged from 1 to 15 responses. Thus, both premature switching, as well as perseveration on Bar A, could be measured under all contingencies. 
Table 1

Summary of Experimental Procedures

\begin{tabular}{|c|c|c|c|}
\hline \multicolumn{2}{|c|}{ Contingency } & Days & $\mathrm{N}$ \\
\hline \multicolumn{2}{|c|}{ Chain } & $32 *$ & 6 \\
\hline & & 4 & 6 \\
\hline Drug A & No-Drug $\mathrm{S}$ & & $3 / 3$ \\
\hline Fade A & Fade S & 10 & $3 / 3$ \\
\hline Tand A & Tand S & $22 *$ & $3 / 3$ \\
\hline Tand $\mathrm{S}$ & Tand A & 4 & $3 / 3$ \\
\hline
\end{tabular}

*The final 2 days at this contingency served as the pretest baseline for each $S$.

Table 2

Mean Standard Deviations Across Experimental Conditions

\begin{tabular}{rrrrc}
\hline & Chain & Fade* & Tandem I & Tandem W \\
\hline S & .8486 & 2.0786 & 2.1872 & 2.1292 \\
$\mathrm{~A}$ & 1.2576 & 3.2804 & 2.6881 & 2.4624 \\
\hline
\end{tabular}

Note $-I=$ Ss stabilized without drug, $W=$ Ss stabilized with drug. *Different $S$ s under drug and nondrug conditions.

Experimental Manipulations. Following stabilization on chain FCN 8-FR 1, pretest baselines were established for two sessions. During pretest, Ss were given $1 \mathrm{mg} / \mathrm{kg}$ IP injections of isotonic saline solution (S) 10 min prior to the start of a session. During the next four sessions (test-drug), Ss were given daily injections of $1 \mathrm{mg} / \mathrm{kg}$ d-amphetamine sulfate (A) IP $10 \mathrm{~min}$ before each test session, and were then returned to predrug conditions for 2 days. Run-length distributions for Bar A responses were recorded during pretest and test sessions, and the extent and pattern of disruption was assessed.

All Ss were gradually switched from chain FCN 8-FR 1 to a tandem procedure which maintained the same response and reinforcement requirements as the chain. This fading procedure occurred in five steps, each step lasting two sessions. During this procedure, the light which had served as the $\mathrm{S}^{\mathrm{D}}$ during the chain was gradually reduced in intensity. During this 10-day period, half of the Ss were given daily saline injections while the other half were given injections of the drug. This latter procedure was conducted to determine whether chronic (daily) injections of the drug interfered with the transition from external- to internal-stimulus control.

Following 10 days of fading, Ss were placed on tandem acquisition for 22 consecutive daily sessions. Those Ss that had received the drug during fade were maintained on the drug, and those Ss which had been receiving saline were maintained on that contingency. From the 23 rd to the 26 th day on tandem FCN 8-FR 1, drug withd rawal or introduction was instituted and effects on Bar A run-length distributions were assessed. A summary of the procedures used throughout the various experimental phases is presented in Table 1 .

\section{RESULTS}

The most consistent finding, across all experimental manipulations, was the loss of stimulus control, as measured by an increase in variability in the Bar A run-length distributions. All individual and group indices of variability increased following injections of d-amphetamine. Table 2 depicts the mean standard deviations obtained during both nondrug and drug conditions. The values cited are for 2 pretest (no-drug) days and 4 test (drug) days. As can be seen in Table 2, the drug increased variability under all contingencies. The largest increases were observed during the fading procedure. It is conceivable, however, that this effect is attributable to the fact that different Ss comprised drug and nondrug conditions and, thus, Ss were not serving as their own controls.

Figure 1 represents the run-length distributions on Bar A during chain FR 8-FR 1. Two pretest (S) sessions and four test (A) sessions for the group, as well as for two typical Ss, are shown. The pattern of responding appears to change very little when switching is under external-stimulus control. There is, however, a slight flattening of the distributions, but no indication of premature switching, (i.e., $\mathrm{FCN}<8$ ). The increased variability is indicated only by a larger percentage of overruns $(\mathrm{FCN}>8)$ and slight flattening of the distribution under drug conditions. The mean number of total responses, as well as the mean number of reinforcements received, decreased somewhat under the drug $(2,624$ to 2,309 and 267 to 221). Thus, perseveration appeared to be specific to overruns on Bar A, and should not be attributed to a general increase in activity indicated by response output.

The upper panel of Fig. 2 represents the two groups' run length distributions during the 10 days of fading procedures. The lower two panels depict the first and last 3 days of tandem acquisition for both groups. Control Ss show much sharper internal-stimulus control than those Ss given d-amphetamine during the same sessions. The distributions for the drug group show fairly flat curves and little indication of tolerance ${ }^{1}$ to the drug. Contrary to the pattern of responding during chain test days, which showed a tendency toward perseveration on Bar A, amphetamine Ss show a much greater tendency for premature switching and little perseverative behavior (i.e., FCN $>8$ ) as compared to controls. These effects, although still present, are attenuated during the final 3 days of tandem acquisition (bottom panel).

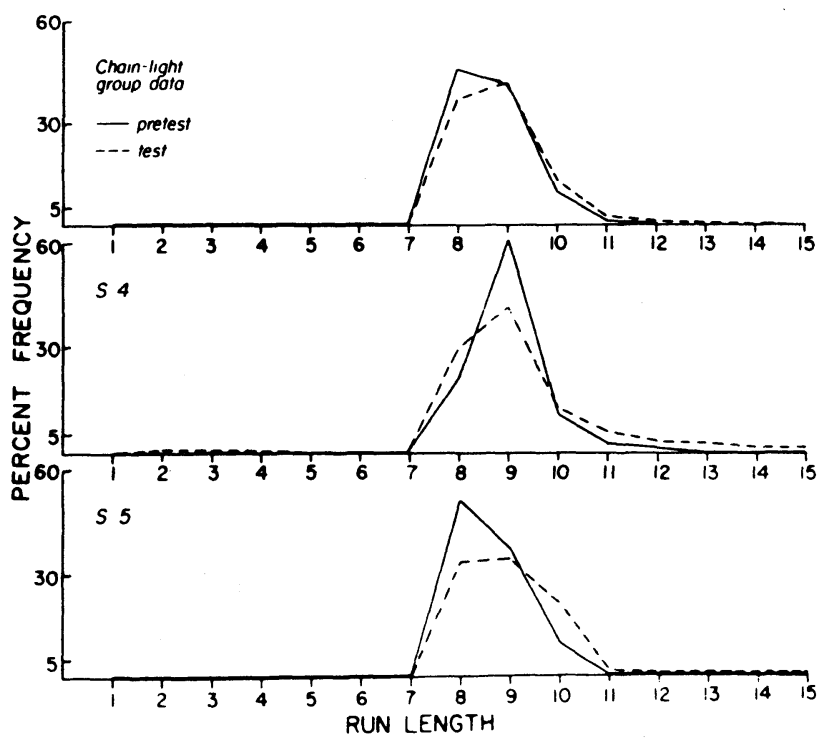

Fig. 1. Bar A run-lenth distributions on the chain schedule of reinforcement. 




Fig. 2. Mean Bar A run-length distributions during fade and tandem acquisition.

Other measures of behavior, as reported in Table 3, indicate much higher responding as well as a greater number of reinforcements per session under drug conditions. This finding consistently occurred, even though the pattern of responding under drug conditions produced poor stimulus and schedule control. Table 3 represents the data concerned with response and reinforcement frequencies during conversion to the use of internal cues. Under all conditions subsequent to the chain, the response and reinforcement frequencies were facilitated under the drug. However, the pattern of responding shows poorer control by internal cues for the drug Ss. In addition, even after 30 days of chronic injection of the drug, tolerance was not observed.

When the drug was removed (see Fig. 3), run-length distributions sharpened and the frequency of premature switching declined.

Upon initial exposure to amphetamine, following stabilization on the tandem (see Fig. 4), a marked flattening of the run-length distributions was observed. One of the Ss (S 6) essentially demonstrated a flat distribution. Premature switching was virtually absent, however, compared to control sessions. Instead, there was a general flattening of the distributions and a marked increase in perseveration on Bar A, especially in S 6.

\section{DISCUSSION}

The findings of the present investigation demonstrate that d-amphetamine not only disrupts behavior maintained by internal cues (tandem), but also affects switching behavior, even when cued by an external discriminative stimulus. Although increased variability in the run-length distribution was shown to be a consistent

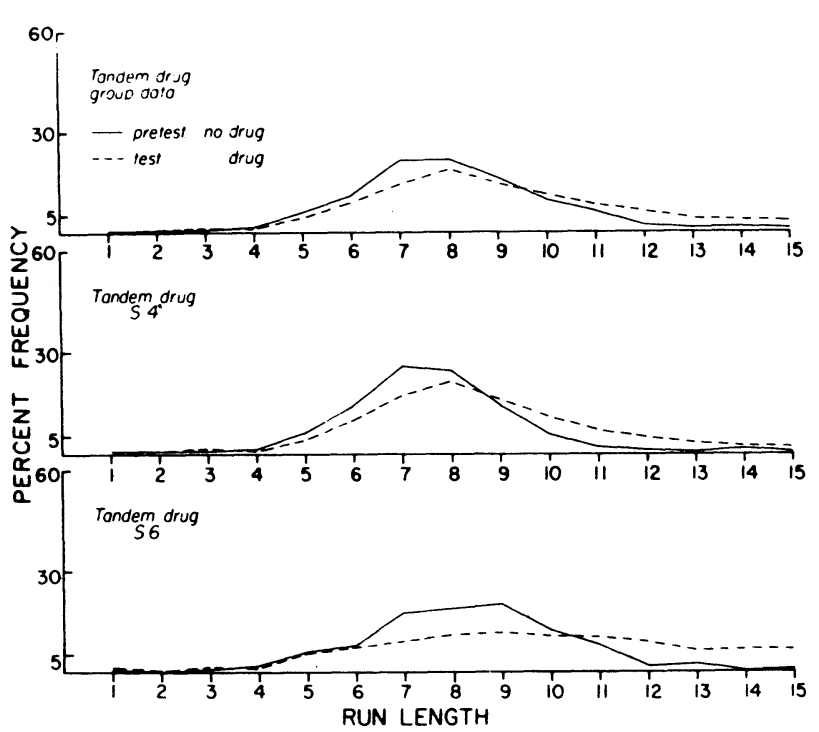

Fig. 3 Bar A run-length distributions for control Ss stabilized without the drug.

effect of the drug, the form of the variance was somewhat different, depending on the extent of, but not the source of, stimulus control.

When switching behavior had stabilized on both the chain and the tandem, marked overruns on Bar A were noted. This effect contrasts with Laties's (1972) finding of premature switching in the absence of external-stimulus control. Where Laties obtained a fairly symmetric flattening of the run-length distributions during the tandem, the results of the present study show an asymmetric change. The effect of d-amphetamine, when switching was signaled by internal cues, was a clearly marked increase in overruns on Bar A and an absence of premature switching.

Premature switching was noted only during acquisition to internal-stimulus control. This effect occurred during the 10 days of fade and gradually declined during the final few days of tandem acquisition. During transition states, stimulus control is far weaker and, therefore, behavior would more easily lend itself to disruption by any new events, whether internally produced by d-amphetamine or in combination with alterations in the source of stimulus control such as a decrease in the intensity of the $S^{D}$, as during the fade. It

Table 3

Mean Response and Reinforcement Frequencies During Acquisition of Internal Stimulus Control

\begin{tabular}{|c|c|c|c|c|c|c|}
\hline & \multicolumn{2}{|c|}{ Fade } & \multicolumn{4}{|c|}{ Tandem Acquisition } \\
\hline & \multirow[b]{2}{*}{ Resp } & \multirow[b]{2}{*}{ RFT } & \multicolumn{2}{|c|}{ First 3 Days } & \multicolumn{2}{|c|}{ Last 3 Days } \\
\hline & & & Resp & RFT & Resp & RFT \\
\hline S & 2240 & 164 & 2027 & 131 & 1909 & 130 \\
\hline A & 2563 & 176 & 4037 & 210 & 3761 & 248 \\
\hline
\end{tabular}

Note $-A=$ amphetamine, $S=$ saline. 


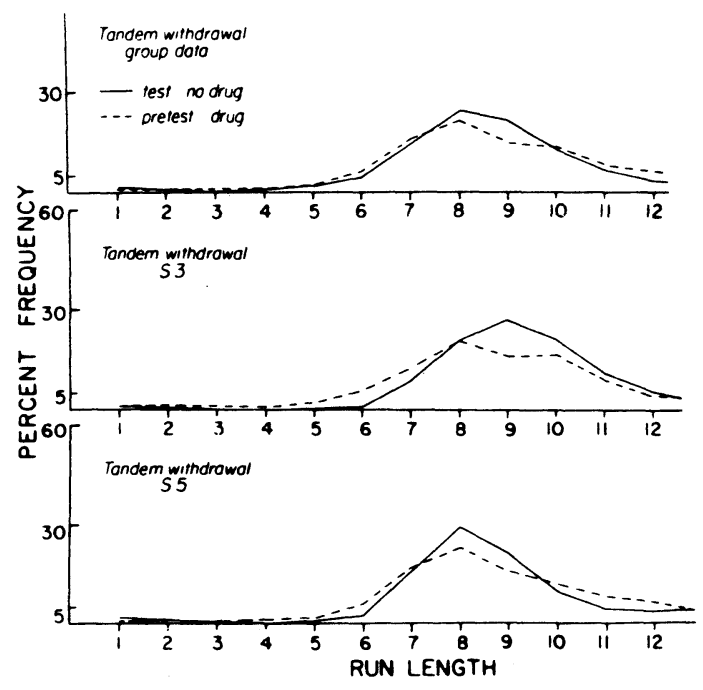

Fig. 4. Bar A run-length distributions for Ss stabilized with the drug.

is conceivable that by initially training his birds on the tandem schedule, Laties was unable to attain strong stimulus control by internal or response-produced cues. The present data suggests that once stable behavior is attained, whether through the use of external or internal events, amphetamine facilitates response perseveration. Perhaps one of the effects of the drug is to stimulate the organism with novel cues (internal), consequently diverting its attention from traditional well-learned ones. Thus, during stable performances, perseveration prior to switching should occur since the $\mathrm{S}$ would be likely to be attending more to these new internal stimuli and less to other discriminable events, whether they be internal or external.

An alternative explanation for the contrasting results is also suggested, especially for Laties's failure to find a change in behavior during the chain. In comparing the results of this study with those of Laties (1972) with pigeons, it becomes apparent that the response selected for study may be a highly critical variable when discussing drug effects on behavior maintained by internal vs external cues. From previous literature on autoshaping (Brown \& Jenkins, 1968), we know that keypecking in pigeons is a highly prepared response in appetitive situations. It would follow that this type of behavior would be more difficult to disrupt than more arbitrary (unprepared) behaviors such as leverpressing. In the area of behavioral pharmacology, limitations on the type of generalizations that can be made are perhaps of more concern than in other lines of behavioral research. We should, therefore, be more critical of the type of response selected for study. It is quite feasible that external-stimulus control may be disrupted by amphetamines to the extent that the behavior is one which is not an evolutionarily prepared one for the organism.

\section{REFERENCES}

Carey, R. J. Disruption of timing behavior following amphetamine withdrawal. Physiological Psychology, 1973, 1, 9-12.

Brown, P., \& Jenkins, H. Autoshaping of the pigeon's key-peck. Journal of the Experimental Analysis of Behavior, 1968, 11, 1-8.

Laties, V. G. The modification of drug effects on behavior by external discriminative stimuli. Journal of Pharmacology \& Experimental Therapeutics, 1972, 183, 1-13.

Laties, V. G., \& Weiss, B. Influence of drugs on behavior controlled by internal and external stimuli. Journal of Pharmacology \& Experimental Therapeutics, 1966, 152, 388-396.

Seligman, M. E. P. On the generality of the laws of learning. Psychological R eview, 1970, 77, 406-418.

\section{NOTE}

1. "Tolerance" is defined as recovery to predrug baseline levels and patterns of responding.

(Received for publication March 26, 1974; accepted May 8, 1974.) 